\title{
LA ASISTENCIA EXTERNA Y SU IMPACTO SOCIOECONOMICO
}

\author{
Víctor Maté de Castro (*)
}

Tal vez pueda parecer un mero ejercicio escolástico preguntarse por la relación entre la ayuda exterior y las posibilidades de desarrollo, cuando han transcurrido más de treinta años desde que se declarara, por NN.UU., la primera década del desarrollo y ya todos comparten que no se observan resultados positivos.

Tampoco se observa, en la gran mayoría de los trabajos cuantitativos, ninguna relación entre los flujos de ayuda y el crecimiento. Una rápida aproximación al respecto nos muestra las escasas posibilidades de impacto sobre el crecimiento que tiene aquélla.

Según los últimos datos consolidados de la OCDE el monto de la ayuda al desarrollo alcanzó los 56.709 millones de dólares (1) y aunque se constituyó en la principal fuente de flujos externos para los países subdesarrollados, eso se debió a la modificación de otras tendencias y no a un mayor esfuerzo de ayuda: de representar el $0,34 \%$ del PNB de 1970 pasó al 0,33\% en 1990 (2). La participación de América Latina en dicha ayuda gira en torno al $10-12 \%$, porcentaje que se redujo en 1993 (los datos consolidados se presentan a principios del 94) y que aún será menor con el incremento de las ayudas a los países del Este y Centroeuropa y a la CEI (caso de los programas PHARE y TACIS, aprobados en 1989 y 1991 respectivamente). En cualquier caso, lo importante es que aquellos datos significan para la región el $0,5 \%$ de su PNB en 1990-91. Si bien dicho porcentaje puede rondar en algunos países, para determinados años (caso de Bolivia, Honduras y Haití - único PMA de la región- en 19901-91) (3) el 10\% de su PNB, lo cierto es que, por ejemplo, eso no alcanzaría para pagar el déficit en cuenta corriente de Bolivia u Honduras en 1992; siendo la relación más desfavorable para el conjunto de América Latina, donde las transferencias netas de recursos resultan unas seis veces superiores a los flujos de ayuda externa (4).

El resultado sería aún más pobre si se tiene en cuenta que parte de esta ayuda no se transforma, se consume (gastos de personal) y que incluso un porcentaje importante (10-20\% según los casos) se gasta en el propio país donante y que en muchos casos, a más de ser siempre el principal cofinanciador,

\footnotetext{
(*) Codirector Instituto Internacional del Desarrollo (ID), Madrid, España.

(1) OCDE, Coopération pour le développement, Ed. CAD-OCDE, París, diciembre de 1991, p. A-8.

(2) Ibidem, p. A-10

(3) Ibidem, pp. A-28 y 29

(4) CEPAL, Balance preliminar de la Economía de América Latina y el Caribe en 1992, Documento Informativo, Santiago de Chile, 18 de diciembre de 1992, pp. 41 y 56 .
}

origina erogaciones para el receptor (caso de los fletes en la ayuda alimentaria que se dirige a América Latina).

No obstante, todas las variables que inciden, tanto en el crecimiento como en el desarrollo, son difíciles de aislar, por lo que nuestro objetivo será analizar el impacto, prestando especial referencia a Latinoamérica, de la ayuda al desarrollo a raíz de las diferentes formas que tiene la misma.

Abordaremos, dadas las limitaciones de espacio con que contamos, tres formas principales: ayuda alimentaria, cooperación comercial para el desarrollo y asistencia técnica (en el área del conocimiento-aplicación y de los proyectos a ejecutar en el Tercer Mundo); mientras que no abordaremos modalidades (que se refieren a sectores, no a formas) muy puntuales como la ayuda de urgencia, a refugiados, referente al medio ambiente (asistencia hoy muy mencionada), etcétera, que en general se realizan a través, aunque con sus peculiaridades, de las tres formas principales señaladas. De la misma manera, también quedan englobadas en dichas tres formas la cooperación privada, aunque la ayuda a través de ONGs y la cooperación empresarial cuentan con suficientes particularidades para quedar muchas veces al margen de nuestro análisis.

\section{LA AYUDA ALIMENTARIA}

La ayuda alimentaria, inicialmente regulada a nivel bilateral (caso de la LP 480 de EE.UU - 1954-), como posteriormente a nivel multilateral (Convenio de Ayuda Alimentaria que es parte del Acuerdo Internacional del Trigo que entra en vigor en 1968), es una forma de utilizar los excedentes agrícolas y racionalizar el comercio de los mismos. Aunque a partir de la década del 70 se irían incorporando a las donaciones otros productos, principalmente lácteos, grasas y aceites, en torno al $80 \%$ de la ayuda alimentaria siguen siendo cereales (principalmente trigo) (5).

Estos aportes en ninguno de los casos alcanza el 1\% de la producción respectiva del Tercer Mundo y en casos como los de la carne y el pescado quedan por debajo del $0,1 \%$. Siendo mayor su impacto sobre la balanza comercial, nunca llegarían a representar, en las necesidades de importación alimenticia de América Latina, los dos dígitos (6).

(5) Las nuevas tendencias en ayuda alimentaria surgidas en los años 80 comprometen muy pocos recursos y están en realidad ligadas a las otras formas de ayuda mencionadas al principio.

(6) FAO, El Estado Mundial de la Agricultura y la Alimentación, Ed. FAOP, Roma, 1987 , p. 14. 
Atendiendo a que los propios donantes reconocen como condición de esta ayuda los excedentes más que las necesidades específicas de cada país (7) y que su impacto es considerablemente reducido (la FAO considera que los requerimientos serían del doble), nos deberíamos preguntar si esta ayuda es necesaria (que se requiera no implica su necesariedad) y qué relación puede tener con las posibilidades de desarrollo.

Existe en el Tercer Mundo una subutilización de los factores evidente: en América Latina resulta que Brasil, por ejemplo, tiene más tierras cultivables que EE.UU. (recuérdese el problema del latifundio en la región). Por tomar el país más pobre de América Latina, Haití, señalemos que la tala de las laderas de las montañas por parte de los campesinos que buscan alguna manera de producir alimentos se da paralelamente a la explotación en los ricos valles de cultivos de escaso valor nutritivo (azúcar, café y cacao) y forrajes (alfalfa). Al igual que el sorgo, que está suplantando a los cafetos en las laderas de las montañas (8) (con el consecuente problema de amalgama en los suelos) son cultivos orientados a la exportación o a la cría de ganado para el consumo de altos ingresos (el Tercer Mundo vende en torno al $90 \%$ de sus proteínas en carne roja y pescado). Incluso se da la extraña situación de que se transporte en avión ganado de Texas a pastar a Haití para luego ser reexportado a EE.UU. (9), con todo lo que ello implica (la producción animal requiere 10 veces más insumos que la vegetal $o$, si se prefiere, «las ovejas se comen a los hombres») (10).

Pese a todo ello, América Latina, como todas las regiones del Tercer Mundo (incluido el propio Sahel, salvo Mauritania, rica en minerales) alcanzan el 1,5 de TMB (Tasa de Metabolismo Basal), es decir, de energía necesaria para mantener el peso del cuerpo en condiciones de reposo de un varón adulto pequeño (11).

El problema es de reparto espacial de los alimentos, de la distribución del ingreso y la demanda efectiva. Si bien el primer problema no alcanza en América Latina la situación de otras áreas donde las posibilidades de transporte, almacenamiento y transformación es inferior (incluso para países como China o India los excedentes empiezan a ser un problema) (12), sí resulta clave el segundo. Ello particularmente en el caso de los países con una distribución del ingreso más regresiva, donde «los grupos afectados por el hambre son demasiado pobres o demasiado débiles políticamente para obtener una parte de los alimentos disponibles, o la sociedad no quiere o puede intervenir» (13).

(7) Puede verse Comisión de las Comunidades Europeas, L'Aide alimentaire de la $\mathrm{CE}$. Instrumen d'une politique de developpement au moyen d'utilisser les excedentes. Europe Information Développement X/76/88, Bruselas, 1988, p. 2 y Comisión de las Comunidades. «La Historia», Cuaderno núm. 2: El Diálogo Europa-Sur, Bruselas, 1984, p. 2.

(8) Banco Mundial, Informe sobre el Desarrollo Mundial, Washington D.C., 1986, p. 20.

(9) Moore Lappé, Frances y Collins, Joseph, «El hambre en el mundo: 10 mitos», en Manifiesto contra el Hambre en el Mundo, Ed. IEPALA, Madrid, 1985, p. 48.

(10) FAO, Agricultura: Horizonte 2000. Ed. FAO, Roma, 1981, p. 36.

(11) Véase Moore Lappé y Collins, op. cit., p. 37 y de los mismos autores, Comer es primero. Más allá del mito de la escasez, Ed. Siglo XXI, México, 1982.

(12) Banco Mundial, op. cit.,, 1986, p. 171; Murdoch, William, La pobreza de las Naciones, Ed. FCE, México, 1984, p. 143.

(13) FAO, op. cit., 1981, p. 23
Evidentemente, la ayuda alimentaria no es necesaria (no existe correlación positiva directa entre excedentes alimenticios y ausencia de hambre) y no favorece ningún tipo de cambio en una estructura social, tenencia de la tierra o distribución del ingreso que nada tienen que ver con las posibilidades de desarrollo. En cualquier caso ello no obsta para que sí tenga diferentes efectos.

En la medida en que el soporte de la ayuda alimentaria son los excedentes se han generado hábitos de consumo en los países subdesarrollados que chocan con las costumbres y la producción local. En el caso de América Latina, resulta que a culturas milenarias del maíz (se ha encontrado polen fósil de maíz con unos 80.000 años de antigüedad), como son la Inca, Maya y Azteca, de Perú, América Central y México; del frijol (denominado por sus proteínas «la carne de los pobres»), caso de México, o de la patata (papa), caso del altiplano andino, se les envía un grano del mediterráneo: trigo (14). Ello, naturalmente con la incidencia de otras variables, como es por ejemplo, en las últimas décadas, la influencia de los sistemas alimentarios verticales de los «agribusiness» (15) ha colaborado en los cambios de las dietas alimenticias y ha presionado sobre nuevas necesidades de importación. Se podría por tanto considerar la ayuda alimentaria como ayuda al desarrollo (en principio al crecimiento) si fuese una ayuda a la balanza de pagos, pero tal cosa no es así si atendemos a que, en su origen, ha creado su propia demanda y nuevas necesidades de importación.

Los excedentes no sólo desequilibran los mercados internacionales; las donaciones desestabilizan el mercado interno de los países subdesarrollados, empujan los precios a la baja, incentivando la pasividad, desalentando la producción y, en definitiva, propiciando el abandono de las tierras por el campesinado (más grave que en Latinoamérica ha sido la situación en ciertos países de Africa, caso de Sudán con las «ayudas» de 1984-85) (16). Socialmente, al ser una solución externa, que además traslada pautas urbanas, fomenta el conflicto y el individualismo, toda vez que limita la solución colectiva de los problemas (17).

\section{COOPERACION COMERCIAL}

Evidentemente, la cooperación comercial sería materia de un artículo específico, por lo que nos centraremos aquí en la cooperación comercial que nace teniendo como objetivo más claro el desarrollo (naturalmente ello a nivel teórico) y dejaremos de lado los acuerdos comerciales bilaterales y los Acuerdos Internacionales sobre Productos Básicos negociados en el marco de la UNCTAD (esto implica que, por

(14) Stakman, E.C., Bradfield, Richard y Mangelsdorf, Paul C., Campaings Against Hunger, Harvard University Press, 1967, pp. 46 y ss.

(15) Puede ser interesante consultar Austin, James, Agribusiness in Latin America, Praeger, New York, 1974.

(16) Von Schuman, Andreas, «El Tercer Mundo víctima de la política agraria de la CE», revista Desarrollo y Cooperación, núm. 5, Bonn, 1987, p. 9.

(17) Goldschalk, Elke y Häbig, Manfred, «Los efectos de la ayuda alimentaria», revista Desarrollo y Cooperación, núm. 1, Bonn, 1989, pp. 8 a 11. También puede verse sobre los efectos de la ayuda alimentaria Maté, Víctor, y Moreno, Mario, "Ayuda Alimentaria: una aproximación crítica», en op. col., Hombre $y$ Medio Ambiente. Ed. SEATLE-Ayuntamiento de Alcobendas, Madrid, España, 1990 , pp. 235 a 249 
ejemplo, toda vez que no analizaremos el Acuerdo del Azúcar tampoco abordaremos casos como el Protocolo del Azúcar de la CEE).

Dada la fuerte correlación que existe entre ingresos por exportaciones y crecimiento, lo que llevó a muchos autores (caso de J. Pincus o H. Johnson, por ejemplo) a acuñar la frase "comercio en vez de ayuda», sí debemos aludir a los mecanismos de estabilización de ingresos por exportaciones (18). Como se sabe, lo que debería haber sido el eje de estos instrumentos fue el Fondo Común de Materias Primas de la UNCTAD que sin embargo, por ahora, no ha prosperado (aunque finalmente iniciaría sus actividades en 1989). Ante esta situación resulta evidente que el mecanismo principal en este ámbito es el STABEX de la CEE (el SYSMIN es para recuperar la producción y exportación de productos mineros a través de proyectos) que pretende estabilizar (reintegrar) la caída, sea por cuántum o precio, del volumen exportado de productos agrícolas (19). Salvo excepciones puntuales, el STABEX sólo alcanza en América Latina a Haití y República Dominicana y, con seguridad, no se extenderá a otros ni siquiera a medio plazo.

El problema del STABEX es que sus fondos no llegan a cubrir las caídas (que cumplen los requisitos para apelar al Sistema) que se operan en los países ACP y por tanto, mucho menos existe la posibilidad de que se extienda a Latinoamérica (sólo para que se ampliara a la República Dominicana España tuvo que hacer importantes esfuerzos y concesiones) (20). Por otra parte, en la medida que la media en la caída se casa en base a los últimos años (21), lo que el STABEX hace es consolidar la caída a largo plazo en los precios (sería un caso de medias móviles), ya que el deterioro en los términos del intercambio es un problema secular y no coyuntural.

Al margen de estos fondos, cuyo impacto resulta reducido, está muy claro que el principal instrumento es el Sistema Generalizado de Preferencia. El SGP, nacido en el marco de UNCTAD II, e integrado en los acuerdos del GATT, implica la abolición o rebaja arancelaria en los países de la OCDE (utilizan el mismo tipo de concesiones, pero las aplicaciones varían) para las exportaciones de los países subdesarrollados.

El SGP (que no es contractual para ningún país de la OCDE o la CEE) tiene diferentes limitaciones que reducen considerablemente su impacto: mantiene cláusulas de salvaguardia y contingentes; en otros casos los países se fijan

(18) Otro mecanismo de interés es el fomento de las importaciones del Tercer Mundo que realizan algunos paises desarrollados (caso de Suecia). Aunque, como es lógico, su impacto es más que limitado.

(19) Art. 147 del Tercer convenio ACP-CEE, Diario Oficial de las Comunidades Europeas, núm. L 86, Luxemburgo, 31 de marzo de 1986, p. 45, y art. 186 del Cuarto Convenio ACP-CEE, revista Le Corrier, núm. 120, Bruselas, marzo-abril de 1990 , p. 49.

(20) López Martinez, Antonio, «El proceso de formación histórica de la Política Comunitaria de Cooperación al Desarrollom, en VV.AA., Política Comunitaria de Cooperación al Desarrollo, Ed. AECI, Madrid, 1992, pp. 29 a 59.

(21) De los últimos cuatro años de «media de los ingresos de exportación», en Lomé III (art. 158 del Tercer Convenio ACP-CEE. Diario Oficial de las Comunidades Europeas, L. número 86, Luxemburgo, 31 de marzo de 1986, p. 47) se ha pasado a los «seis años anteriores a cada año de aplicación, excluyendo los dos peores años" (art. 197, Cuarto Convenio ACP-CEE, revista Le Courrier, núm. 120, Bruselas, marzo-abril de 1990, p. 51). Modificación que si bien mejora el Sistema no invalida las limitaciones que nosotros señalamos. autolimitaciones que permiten que se mantenga el SGP para el bien en cuestión a cambio de una fuerte caída en las exportaciones (caso de Brasil con el acero); choca con los efectos de la progresión arancelaria de los países desarrollados; deja al margen el hecho de que los principales sectores de exportación manufacturada del Tercer Mundo, y más aún de América Latina, son sectores dinamizadores y decadentes que encuentran en los países desarrollados fuertes barreras no arancelarias y paraarancelarias (estas últimas afectan un cuarto aproximadamene de las importaciones que realizan los países desarrollados). Junto al acero, la química, etc., el caso más patente es el de los textiles, que explica un tercio de las exportaciones del Tercer Mundo y que ha sufrido fuertes restricciones con el Acuerdo Multifibras (AMF) (22).

Todas estas limitaciones resultan más considerables en América Latina que en otras áreas del Tercer Mundo (23) y la región, al igual que otras en desarrollo, participa cada vez menos en el consumo aparente de los países desarrollados. La creación comercial del SGP es mínima (24), se concentra en unos pocos países y sólo la cláusula de nación más favorecida crearía más comercio que el SGP (25).

Si tomamos uno de los SGP más interesantes para Latinoamérica (el de la CEE) (26), resulta que afecta menos de un cuarto de las exportaciones de la región al mercado comunitario (menos del $4 \%$ de todas las exportaciones latinoamericanas), de las cuales una parte mayoritaria se hubiesen exportado igual a dicho mercado. Siendo el comercio clave para el desarrollo, en principio crecimiento, del Tercer Mundo (recuérdense las demandas del NOEI), resulta evidente que las posibilidades del SGP son ínfimas y por áreas se concentra en unos pocos países (según los años en Brasil, Chile, Venezuela y México en el caso de América Latina).

Por otra parte el SGP no atiende en ningún caso elementos clave del comercio del Tercer Mundo como la baja elasticidad ingreso de la demanda de los productos exportados por dicha región; que las corrientes monetarias estén determinando las comerciales y no a la inversa; los cambios en la producción y los productos de los países desarrollados (miniaturización de productos, sustitución de materias primas, etcétera); el mayor peso de los servicios en el producto final; entre un gran número de problemas. Menos aún que la relación «entre tipos de productos» atiende a la relación entre «tipo de países» (27). Planteemos esto en términos de concentración del progreso técnico, de la productividad y por tanto del ingreso (tipo tesis Singer-Prebisch), de térmi-

(22) Puede verse un análisis más extenso en Informe de Investigación, Posibilidades y Perspectivas de la Cooperación Comunitaria frente a las demandas de América Latina, Instituto Internacional del Desarrollo (ID)-Agencia Española de Cooperación Internacional (AECI), Madrid, 1992, pp. 278 y ss.

(23) CEPAL, El proteccionismo de los paises industrializados: estrategias regionales de negociaciones y defensa, DOC. LC/G 1459, Santiago de Chile, 8 de junio de 1987.

(24) Brown, Drusila K., «Trade Preferences for Developing Countries: A Survey of Results», The Journal of Development Studies, vol. 24, núm. 3, Londres, abril de 1988 , páginas 347 y ss.

(25) Estudio realizado por la Secretaría de la UNCTAD, Revitalizing development, growth and international trade: assessment and policy options, TD/328/Add. 1, TD/328/Add. 3, TD/328/Add. 4, Ginebra, 23 de febrero de 1987.

(26) Puede verse una aproximación al respecto en Maté, Victor, «América Latina en la Cooperación al Desarrollo Comunitario», revista Desarrollo y Cooperación, número 2, Bonn, 1989, pp. 7 y ss.

(27) Singer, Hans, y Ansari, Javed, Paises Ricos y Pobres, Ed. Pirámide, Madrid, 1982, p. 37. 
nos del intercambio factoriales dobles (28), de circulación del excedente y la posibilidad de eludir la ley del valor (29) o de tasa de ganancia (30), o desde perspectivas más elementales al estilo temporal-espacial de Gunder Frank (31).

\section{ASISTENCIA TECNICA}

Esta asistencia, que implica en los años 90 una cuarta parte de la AOD, incluye tanto el desarrollo del capital humano (formación y asesoramiento en los países subdesarrollados o en los propios países desarrollados) como la realización de proyectos de desarrollo en el Tercer Mundo (y, por tanto, en general, de suministro de algún tipo de equipamiento). Aunque en gran medida los análisis de ambas se entrecruzan, necesidades de claridad expositiva nos recomiendan tratarlas separadamente.

La totalidad de dicha asistencia técnica para América Latina no ha alcanzando en lo que va de los 90 , en ningún año, a los 1.000 millones de dólares, lo que implica que ni siquiera solventaría la brecha ahorro-inversión, al margen que del flujo total los gastos podrían llegar a más de la mitad del mismo. Por otra parte, debemos recordar que la existencia de unos flujos financieros no implica su transformación automática en capital. Aunque vaya ligado a un proyecto, el flujo de ayuda puede en realidad estar financiando el consumo.

\section{III.1. Asistencia técnica a través de proyectos de desarrollo}

Excepción hecha de los países que orientan su ayuda bilateral a través del «modelo nórdico» y de la ayuda multilateral, la asistencia a través de proyectos muestra un claro cuantitativismo (se atiende a la mayor presencia por sectores y países que a la calidad de la misma). En cualquier caso no nos interesan aquí las evaluaciones de proyectos, que proliferaron particularmente desde la década del 70 , ya que el interés de una inversión específica o las consecuencias sobre un grupo objetivo particular no nos dicen nada sobre las posibilidades de desarrollo; al margen de que cualquier ayuda exterior va a financiar el gasto marginal, o sea, el proyecto más marginal (el que no se hubiese hecho sin dicho flujo accesorio), no el que se evalúa en la práctica. Atendiendo a la hipótesis de que una tasa de inversión anual del $25 \%$ del PIB permitiría un incremento del ingreso nacional del $2 \%$ (32) o la más optimista que señala una relación del $15 \%$ del PIB para el $5 \%$ de crecimiento (33) (esta última sería una relación elevada para la mayoría de los países latinoamericanos), aquellos 1.000 millones de dólares tendrían un

(28) Resulta de interés ver Griffin, Keith, Desigualdad internacional y Pobreza Nacional, Ed. FCE, México, 1984, pp. 135 y 136.

(29) Marini, Ruy Mauro, Dialéctica de la Dependencia, Ed. Era, México, 1974

(30) Emmanuel, Arghiri, El intercambio desigual. Ensayo sobre los antagonismos en las relaciones económicas internacionales. Ed. Siglo XXI, México, 1972.

(31) Interpretación que sigue presente en los últimos trabajos del autor. Véase Gunder Frank, Adnré, El desafio de la crisis. Ensayo sobre crisis económica mundial, ironias políticas internacionales y desafio europeo. Ed. IEPALA, Madrid, 1988.

(32) Jalée, Pierre, El Tercer Mundo en la economía mundial, Ed. Siglo XXI, México, 1980 , p. 103.

(33) Coyle, Cushman, Desarrollo Nacional y su Funcionamiento, Ed. UTEMA, México, 1963, p. 66. escaso impacto sobre el crecimiento de la región. En cualquier caso se trataría de ver la relación capital-producto incremental que, por todo lo que iremos viendo, es menos optimista aún.

Aunque exista un diálogo entre donante y beneficiario, las prioridades (sectores, modalidades, etcétera) y, en fin, la política de ayuda, las define aquél. Esto implica que, naturalmente, por más condicionado y escaso que sea el recurso que aporta el país donante, cualquier país dependiente volcará sus esfuerzos en aquel sector en el que se le solicite un esfuerzo para la realización de un proyecto determinado. En este sentido se suele olvidar que el principal cofinanciador, cuando no «donante», es el propio país receptor, que aportará buena parte de los recursos (tierra, determinada infraestructura existente, personal, etcétera). De esta manera, la maximización de unos recursos propios a través de la ayuda exterior tendrá un costo elevado para el receptor y significará un condicionante sobre sus políticas públicas (decisiones), sus intereses y sus prioridades. Incluso, como señala Elmandjra, «la programación, la administración y la supervisión de la ayuda (que identifica con la que se realiza a través de proyectos) significan en muchas ocasiones la intromisión en la política económica de los planes y la restricción de la flexibilidad de sus planes» (34). Por otra parte, al tratarse de ayuda ligada (no a las exportaciones pero sí a un proyecto) implicará la exportación de conocimientos técnicos, ergo unos servicios, una información y hasta una cultura, es decir, a corto plazo, bienes.

Ahora bien, teniendo en cuenta que existen notables diferencias entre países y tipo de AOD, está claro que la prioridad de la asistencia técnica es el sector rural (la asistencia en otros sectores: infraestructura y social, por ejemplo, también está formulada teniendo en cuenta aquella prioridad). Esto, al margen de poder implicar (en caso de que el impacto de la asistencia fuese realmente importante) un sector industrial desfasado tiene otras consecuencias. El modelo que se sigue es la agricultura de alimentación, o sea la interiorización del sector agrícola, lo que tendría sentido si se interiorizaran los insumos, pero en tal caso, como señala Robinson, el país en cuestión no recibiría un solo dólar más de ayuda. Por otra parte, tal agricultura se piensa a través de la mecánica de mercado (crédito, precios elevados y estables, etcétera) que es ni más ni menos el fin de la autosuficiencia alimentaria en Latinoamérica (tampoco existe necesariedad entre desarrollo y mercado o desarrollo y capitalismo). El mercado orienta inevitablemente la producción hacia lo rentable, la demanda efectiva condicionará la estructura productiva en dirección del consumo de los grupos de más altos ingresos, los cultivos industriales y la exportación (35), fomentando la concentración del capital, la redistribución regresiva del ingreso y la concentración espacial. Ejemplo de ello es el proceso de ganaderización en Latinoamérica, o específicamente el caso del banano en Ecuador (36) o el algodón y el tabaco en Colombia (37).

(34) Elmandjra, Mahdi, «La ayuda al desarrollo como obstáculo al autodesarrollo», Revista Desarrollo, núm. 13, Madrid, 1988, p. 17.

(35) Barkin, Davir, y Suárez, Blanca, El fin de la autosuficiencia alimentaria. Ed. Océano-Centro de Ecodesarrollo, México, 1985, pp. 210 y 22.

(36) Salgado, Germánico, "Lo que fuimos y lo que somos», en VV. AA., Ecuador Hour, Ed. Siglo XXI, Bogotá, 1978, p. 30.

(37) Ocampo, José Antonio; Bernal, Joaquín; Avella, Mauricio, y Errázuriz, Maria, 
Tampoco se trata de cambiar la prioridad de esta ayuda y primar al sector industrial, que, por ejemplo, tienen mayores consecuencias sobre las necesidades futuras de financiamiento externo, sino que, no se pueden definir políticas sectoriales, sin definir una política de desarrollo, que incluye la situación económica interna y externa e implica la valoración sociopolítica (38). Por esto, que a todas luces deberían definir las autoridades soberanas de los países latinoamericanos, ni siquiera es fácilmente discutible con los países desarrollados. Estos escapan a los foros amplios y prefieren, como señala CEPAL, el tratamiento sectorial en los foros especializados (lo que ocurre, por ejemplo, dentro del sistema de NN.UU.) donde aquéllos dominan.

\section{III.2. Formación, asesoría e investigación}

Esta modalidad de asesoramiento científico-técnico vuelve a chocar (incluimos estudiantes y «stagiaires», expertos y voluntarios - entre los cuatro superan las 200.000 personas- y gastos en ciencia al servicio del desarrollo), al margen de con la escasez de los recursos y con el cuantitativismo señalado, con el hecho de que ambos procesos sean determinados por los países desarrollados.

En este sentido se deja en general al margen la base de lo que serán las ventajas comparativas en el futuro: biotecnología, biogenética, informática, microelectrónica, etcétera (39), algunas de las cuales amplian la propia capacidad de I+D (capacidad, confiabilidad, almacenamiento y recuperación) (40). Esto no implica que los programas se deban orientar a los campos señalados pues «la técnica constituye un sistema global» (41). Tampoco se debe oscilar entre el «modelo occidental de concentración industrial y de tecnología de punta» y el hoy muy difundido «modelo de desarrollo autocentrado». Existen puntos intermedios entre desarrollo autónomo y «modelo occidental», puntos que no se pueden definir externamente (desde la ayuda exterior) y para todo el Tercer Mundo (como hacen la mayoría de los programas) como si se tratara de un solo esquema científico-técnico (42), sino que se debería configurar en interacción con unas caracterís-ticas socioeconómicas, políticas y culturales (43).

El problema es por tanto de todo el proceso conocimiento-aplicación-comercialización: hay que desarrollar un proceso de endogenización gradual de la base científico-tecnológica donde se integre una capacidad de investigación (la mayoría de los centros latinoamericanos no alcanzan la denominada «masa crítica») transformar los resultados de

"La consolidación del capitalismo moderno», en José Antonio Ocampo (editor), Historia económica de Colombia, Ed. Siglo XXI, Bogotá, 1987, pp. 280 y ss. Sobre los ejemplos citados puede verse un análisis más extenso en Maté, Víctor, La estructura social en la Región Andina, Ed. Akal, Madrid, 1992, pp. 20 y ss.

(38) Vuskovic, Pedro, Opciones actuales del desarrollo latinoamericano. CEPALILPES, DE 58, Santiago de Chile, 19801 p. 126.

(39) Puede verse al respecto, VV. AA., La tercera revolución industrial. Impactos internacionales del actual viraje tecnológico, Ed. GEL, Buenos Aires, 1986.

(40) Rada, Juan F., La microelectrónica, la tecnologia de la información y sus efectos en los paises en vía de desarrollo, Ed. El Colegio de México, México, D.F., 1983, p. 64.

(41) Gille, B., Histoire des techniques, Ed. La Pléiade, París, 1978.

(42) Salomon, Jean-Jacques, «Science, technologie et développment: le problème des priorités), revista Tiers Monde, T. XXVII, núm. 105, Paris, enero-marzo, 1986, pp. 214 y 216.

(43) Ominami, Carlos, «Tercera rev lución industrial y opciones de desarrollo», revista Integración Latinoamericana, año 12, núm. 123, Buenos Aires, mayo de 1987, pp. 57 a 69. investigación a tecnologías generadas localmente o adaptadas (recuérdese aquí el caso de Latinoamérica con su inadecuación tecnológica o de capital y de escala -mercados-) (44) y capacidad empresarial para adaptar nuevas tecnologías a las tradicionales.

Ante esto, la realidad es que el pago por transferencias de tecnología suelen ser en muchos países subdesarrollados (por la situación, como señalan Myurdal o Griffin, monopólica de los países desarrollados) un grave problema en erogaciones por licencias, patentes y similares, que, por ejemplo, en casos como los de Brasil, Colombia, México o Perú superan a los gastos en investigación.

Frente a estos elementos, la ayuda externa no mitiga (menos soluciona) ni se ha pretendido como su objetivo, elementos básicos de la situación: el proveedor de la patente adquiere el monopolio en la fabricación del producto amparado (no se puede patentar uno igual o similar), aun cuando dicho producto no se fabrique nunca en el país (el $90 \%$ de las patentes de extranjeros en el Tercer Mundo no se utilizan nunca) (45). El titular del derecho adquiere en exclusiva las posibilidades de importación (la transnacional se resguarda de competencia). No existe reglamento o no se aplica (caso de Colombia o Perú) que obligue a utilizar la patente (es una traba a la producción). Es el concedente el que tiene derecho a prorrogar o no el contrato de licencia (poder absoluto para el fabricante). Por la cláusula de amarre, insumos y bienes intermedios deben ser adquiridos al concedente. Se ponen límites al volumen de producción o se deben entregar al concedente todas las mejores o inventos conseguidos con la tecnología en cuestión. La falta de medios en el país subdesarrollado permite patentes cuyos derechos han caducado (46). Por incapacidad de los países del Tercer Mundo que lo intentan (caso de la decisión 24 del Grupo Andino) o presiones de los países desarrollados (caso de la programación de computadores con Estados Unidos) (47) resulta muy difícil invertir estos problemas.

Si sumamos, a lo reducido de la ayuda exterior, los restantes problemas del proceso conocimiento-aplicación-comercialización, resulta evidente que tampoco la información en los países desarrollados (menos de un 3\% de la AOD en «stageries» y becas), y sin que de ello se siga la necesariedad del conocimiento y la formación puramente autocentrados, resultan una alternativa a las posibilidades del desarrollo.

Por el contrario, el problema estaría en evitar la denominada fuga de cerebros («transferencia inversa de tecnología o brain drain») (48). Tomando la década del crecimiento hasta la primera crisis del petróleo, resulta que, según la

(44) Puede verse Paniev, Yuri, «La cooperación técnica y cientifica», revista América Latina, núm. 10, Moscú, 1987, p. 11; y también es de interés consultar Fanjnzybbert, Fernando, La industrialización trunca de América Latina, Ed. Centro Editor de América Latina - Centro de Estudios Transnacionales, Buenos Aires, 1983, capitulos III y V

(45) Según datos de la UNCTAD, op. cit. TD/328/Add. 4

(46) Sagasti, Francisco R., y Guerrero C., Mauricio, El desarrollo cientifico y tecnológico de América Latina. Ed. BID-INTAL, Buenos Aires, 1974, pp. 39 a 42.

(47) Ventura-Días, Vivianne, «La vieja lógica del Nuevo Orden Económico Internacional», Revista de la CEPAL, núm. 37, Santiago de Chile, abril de 1989, p. 115.

(48) Véase un ejemplo concreto sobre sus consecuencias en el periódico La Nación, Edición Internacional, «Habría demoras en el Plan Nuclean», Buenos Aires, 17-VIII-1987, p. 5. 
UNCTAD, entre 1962 y 1972 emigraron desde el Tercer Mundo a los tres principales países receptores (EE.UU., Gran Bretaña y Canadá) más de 230.000 científicos y aproximadamente otros 15.000 a Europa Occidental. Proceso que desde fines de los 80 se empieza a dar con cierta importancia, incluso a nivel de mano de obra calificada; lo cual es lógico si se tiene en cuenta que, en este sentido, existe un potencial productivo que no se puede emplear y que incluso se habla ya de una «sobrecalificación relativa de la fuerza de trabajo» (49). Si se toman otros datos de emigración a EE.UU., Francia y Canadá, siguiendo con la misma década (en este caso 1962-66) resulta que el porcentaje de ingenieros que emigra alcanza su nivel más elevado en el caso de Chile con el 30\%; en el caso de los científicos naturales el récord lo establece Venezuela, donde la emigración de los egresados alcanzó casi la mitad (48\%). En el caso de los médicos, como en el de los científicos sociales, la proporción más elevada corresponde a Colombia con el 23 y $9 \%$ respectivamente. Esto implica que, por ejemplo, la emigración de físicos y cirujanos del Tercer Mundo a los EE.UU. en 1971-1972 representó el 51\% de la capacidad total de ese país en dicho sector (50). Todo lo cual reduce el ingreso en los países subdesarrollados a la vez que incrementa el ingreso de los profesionales que no emigran, lo cual acrecienta la desigualdad en la distribución del ingreso (51), obstáculo claro en las posibilidades del desarrollo.

Llegamos así a una conclusión muy extendida en América Latina, que raramente se atiende o se hace marginalmente en la asistencia técnica. La región necesita una base propia y autónoma, un conocimiento que no sea recibido, sino que se ajuste a sus características sociales y a su específica dotación factorial (terminar con la «fuga interna de cerebros») (52). «La cooperación que América Latina solicita (...) debe estar orientada a permitir que la región logre (una mayor) autonomía. No debe (...) constituir una repetición de los errores de la historia, cuando el conocimiento, el valor fundamental, fue recibido y no generado por los agentes productivos y sociales de la región» (53).

\section{UNA CONCLUSION «IN TEMPORE»}

Resulta evidente, no sólo por la contrastación empírica que anotábamos al iniciar este artículo, que no es la ayuda exterior la otra cara del desarrollo. Siendo escasas las posibilidades de impacto (para el crecimiento) resultan aún más discutibles las orientaciones que adoptaría dicho impacto (relacionado ya sí con las posibilidades de desarrollo). Tampoco la política general de ayuda exterior ha sido diseñada con la participación directa de América Latina, y no se adapta en lo más elemental a las demandas de la región (tomando como articuladores y agregadores de éstas al SELA, CEPAL, los diferentes GRULAS, o cualquier otra instancia oficial de menor interés que represente el subsistema latinoamericano). Si como señala Santa Cruz, se trata de «cooperar o perecen», resulta evidente que no se ha co-operado («operado conjuntamente»). Sólo a raíz del acuerdo (entre una idílica armonía y el conflicto) en torno a flujos comerciales, financieros, de ciencia y tecnología, etcétera, se puede conseguir algún impacto sobre las posibilidades de desarrollo de América Latina y, claro está, también va en ello, para los países desarrollados, y particularmente para Europa, buena parte de su bienestar. Hoy, ni la cooperación, ni la ayuda exterior, son esto.

\section{RESUMEN}

Maté de Castro trata de definir la relación que se da entre la ayuda externa al desarrollo y las posibilidades de que éste se concrete en América Latina, concluyendo, después de un análisis de los tres tipos de ayuda que existen actualmente, que la cantidad y el propósito de dicha asistencia no es suficiente para incrementar el crecimiento económico en esta región.

\section{ABSTRACT}

Maté de Castro tries to concrete the relationship between the external assistance and the possibilities of development in Latin America, and he concludes, after an analysis of the three types of assistance actually existing, that the amount and proposal of this one is not sufficient to improve the economic growth in this region.

(49) Martner, Gonzalo (coordinador), América Latina hacia el año 2000. Opciones y Estrategias, Ed. Nueva Sociedad-UNITAR-PROFAL, Caracas, 1986, p. 83.

(50) Watanaba, S., The Brain from Developing to Developed Countries. Ed. OIT, Ginebra, 1969

(51) Un análisis de interés al respecto puede verse en Griffin, Ketih, op. cit.,, pp. 44 a 46.
(52) Puede verse Ferrer, Aldo, «Nuevos Paradigmas Tecnológicos y Desarrollo Sostenible: Perspectiva Latinoamericana), revista Comercio Exterior, vol. 43, núm. 9, México, septiembre de 1993,pp. 807 a 813.

(53) Basombrio, Ignacio, América Latina y la CEE, opciones para el desarrollo comercial (mimeo). Lima, 1987, p. 168. 